\title{
НАСЕЛЕНИЕ РОССИИ В ХХІ В.: КОЛИЧЕСТВЕННЫЕ И КАЧЕСТВЕННЫЕ ХАРАКТЕРИСТИКИ
}

\author{
Русанова Н.E.
}

Традиционно значение населения как фактора сочиальноэкономического развития оченивалось по количественным параметрам, однако на постиндустриальной стадии на первый план вышли характеристики человеческого капитала. Хотя общие количественные индикаторы свидетельствуют об улучшении ситуачии со здоровьем и образованием населения, качество их в условиях демографического старения не может считаться благоприятным из-за снижения потенциала здоровья и структурного несоответствия образования потребностям хозяйственного развития.

DOI: $10.20537 /$ mce2019econ07

Введение. Традиционный подход к оценке населения как фактора производства долгое время был основан на учете его численности. Считалось, что чем больше населения в стране - тем лучше, и только в конце XVIII - начале XIX вв. обратили внимание на то, что численность населения может оказаться чрезмерной относительно возможностей прокормить себя. Первое объяснение такому несоответствию было дано Т. Мальтусом в его законе народонаселения (1798 г.), что можно считать первой попыткой постановки задачи соответствия качества населения требованиям экономического развития; позже выводы Мальтуса сильно критиковались К. Марксом.

В современной России о проблеме количества населения на государственном уровне заговорили в 1993 г., после того, как впервые была зафиксирована депопуляция (естественная убыль населения). В научной среде об этом говорили и раныше, так как рождаемость и темпы прироста населения снижались почти весь XX в., и в результате в XXI в. Россия вступила со стабильным трендом снижения общей численности населения.

Итоговая численность населения зависит от трех составляющих: естественного прироста (разности между рождаемостью и смертностью), миграционного прироста (разностью между числом 
иммигрантов и эмигрантов) и административно-территориальных преобразований (изменение границ). За 2000-2018 гг. влияние этих составляющих было различно:

1. естественный прирост изменился от депопуляции до небольшого превышения рождаемости над смертностью и новой депопуляции;

2. миграционный прирост снижается после всплесков начала века;

3. административные границы расширились после присоединения Крыма.

Результирующей тенденцией стало снижение численности населения. Вопрос: соответствует ли это задачам текущего социальноэкономического развития России и его перспективам?

Для ответа необходимо принять во внимание, что современная экономика - это экономика постиндустриальная и инновационная, а инновации реализуются, прежде всего, молодежью. Инновации способствуют росту производительности общественного труда, что несколько снижает остроту проблемы увеличения численности населения, в определенном смысле, переводя ее из области хозяйственной в эмоциональную, и приводят к необходимости повышения качества населения.

Понятие качества населения определяется на основе принципов теории человеческого капитала, включая, при любой трактовке, здоровье и образование (чем население «здоровее» и «образованнее», тем выше его качество). Для демографии как науки параметры здоровья и образования населения изначально не были приоритетными, хотя началась она именно с построения таблиц смертности. Одной из причин было то, что до XIX в., когда произошел эпидемиологический переход (от внешних причин смертности к внутренним) и эмпирически выявилась взаимосвязь между образованностью и здоровьем, влиять на здоровье населения было практически невозможно, о чем говорят катастрофические эпидемии Средневековья (например, чума в Европе в XIII-XIV вв.). Только медико-биологические прорывы XIX-XX вв. позволили регулировать такие важные демографические параметры как уровень смертности и продолжительность жизни.

Результаты. В XXI в. во всех странах качество населения регулируется медико-биологическими технологиями, а также государственной системой образования и здравоохранения. В России это особенно ярко видно на примере здоровья: такие показатели, как 
Русанова Н.Е. Население России в ХХІ в.: количественные и качественные.., стр. 75-82 Rusanova N.E. Population of Russia in XXI century: quantitative and qualitative..., pp. 75-82

продолжительность жизни, младенческая и материнская смертность, рождаемость улучшаются именно благодаря масштабному распространению среди населения современных методов лечения и профилактики заболеваний.

Общие количественные индикаторы свидетельствуют об улучшении здоровья населения России - за 2000-2018 гг. выросла средняя продолжительность жизни, сократилась смертность, уменьшился гендерный разрыв, однако специальные коэффициенты и качественные показатели говорят не просто о неравномерности проявления этой тенденции для разных категорий населения, но даже о еe противоречивости, так как ухудшилась повозрастная смертность мужчин, усилилась региональная дифференциация и проч. Общей тенденцией можно назвать сохранение тенденции снижения потенциала здоровья российского населения, выявленной Н.М. Римашевской в начале 2000-х гг. В этих условиях возрастает осознание каждым членом общества ответственности за свое здоровье, т.е. самосохранительного поведения, основанного на формировании установок по укреплению собственного здоровья и профилактике заболеваний.

Самосохранительное поведение приобретает особое значение на фоне массового роста неинфекционных заболеваний (НИЗ), распространение которых во всем мире приобрело характер эпидемии с высокой летальностью. ВОЗ объединяет в НИЗ сердечно-сосудистые заболевания (инсульт, инфаркт и проч.); злокачественные новообразования (онкологические заболевания); хронические респираторные заболевания (хроническая обструктивная болезнь легких, астма и проч.); диабет. В РФ в 2015 г. на долю НИЗ (без диабета) пришлось более $2 / 3$ смертей (в трудоспособном возрасте этот показатель не превысил половину) (рассчитано по [3, с.29-30]). Заболеваемость НИЗ растет быстрее, чем другими болезнями; более всего это касается сахарного диабета и новообразований, особенно злокачественных, в группе 20-39 лет.

Базовые характеристики здоровья человека определяются при рождении и формируются до начала трудоспособного возраста, в течение 15 лет, на протяжении которых параметры качества населения меняются неоднократно в связи с последовательным выполнением на данном этапе жизненного цикла трех функций: самосохранительной (здоровье), образовательной (обучение) и репродуктивной (рождаемость). 
Главным результатом деятельности системы здравоохранения на всех уровнях является рост продолжительности жизни. За последнее десятилетие ожидаемая продолжительность жизни (ОПЖ) увеличилась более чем на 5 лет: в 2017 г. она составила 72.68 лет (рост на 0.81 лет по сравнению с 2016 г. - 71.87 лет), у мужчин - 67.58 лет (рост на 1.08 лет, в 2016 г. - 66.50 лет), у женщин - 77.62 лет (рост на 0.56 лет, в 2016 г. - 77.06 лет). Во многом это обусловлено снижением смертности в трудоспособном возрасте, хотя она все еще остается высокой: за 2017 г. по сравнению с 2016 г. снизилась на 8.5\% (с 517.6 до 473.4 на 100 тыс. человек трудоспособного возраста). Последовательно снижается и разница между ОПЖ мужчин и женщин, которая в 2011 г. составляла 11.57 лет, в 2016 г. - 10.56 лет, в 2017 г. - 10.04 лет [2].

В 2017 г. достигнуты исторические минимумы по показателям материнской и младенческой смертности: материнская смертность снизилась до 7.3 на 100 тыс. родившихся в 2017 г. Младенческая смертность уменьшилась до 5.5 на 1000 родившихся живыми в 2017 г. [2].

Снижение смертности произошло от всех основных причин, в том числе от социально-значимых заболеваний и от НИЗ: по сравнению с 2016 г. на 20.5\% (6.2 на 100 тыс. населения) от туберкулеза, на $13.9 \%$ от болезней органов дыхания (41.3 на 100 тыс. населения), на 5.1\% от болезней системы кровообращения (584.7 на 100 тыс. населения), на $3.6 \%$ от новообразований (196.9 на 100 тыс. населения) [2].

Одной из проблем здоровья населения трудоспособного возраста остаются нарушения репродуктивного здоровья, которые встречаются реже, чем НИЗ, но имеют большую демографическую значимость, поскольку препятствуют росту рождаемости. Здесь важны такие аспекты как вспомогательные репродуктивные технологии (ВРТ), аборты и инфекции, передаваемых половым путем (ИППП), в том числе ВИЧ. ВРТ направлены на увеличение числа родившихся и изменение их качества, аборты, напротив, снижают потенциальное количество новорожденных, ИППП и ВИЧ непосредственно не влияют на количественные параметры рождаемости, увеличивая ее не более чем на $5 \%$, но ухудшают качественные, поэтому тенденции развития этих компонентов репродуктивного здоровья сегодня различны.

ВРТ становятся популярнее — в 2015 г. доля детей, родившихся после ВРТ в России, составила не менее $1.5 \%$ против $0.93 \%$ в 2013 г. [5,6]. Этому способствовало включение ВРТ в систему обязательного медицинского страхования (ОМС), сделавшее их более доступными, 
Русанова Н.Е. Население России в ХХІ в.: количественные и качественные.., стр. 75-82 Rusanova N.E. Population of Russia in XXI century: quantitative and qualitative..., pp. 75-82

однако одновременно возникли и новые этические вопросы, связанные с возможностью выбора пола ребенка при экстракорпоральном оплодотворении (ЭКО), морально-психологическими проблемами репродуктивного донорства и суррогатного материнства, взаимодействием врача и пациента в программах ВРТ, поздним материнством.

Общемировой демографической характеристикой сегодня является старение населения - в России пожилые и старые люди составляют более трети населения, а $13.5 \%$ граждан достигли возраста 65 лет (рассчитано по [7]). Процесс демографического старения России обусловлен в первую очередь не увеличением продолжительности жизни, как в большинстве развитых стран, а низкой рождаемостью и высокой смертностью в трудоспособном возрасте, из-за чего среди первого поколения россиян, которые достигнут нового пенсионного возраста в 65 и 63 года, не дожить до пенсии могут 17.4\% мужчин и $6.5 \%$ женщин [9]. ОПЖ на пенсии при нынешнем пенсионном возрасте составляет 25,8 и 16 лет для женщин и мужчин соответственно, по данным Росстата на 2016 г. [9]. В России только 59.3\% мужчин, родившихся в 2016 г., доживут до нового пенсионного возраста, а до 60 лет - 69.4\%, а в Германии до 65 лет доживут $84.9 \%$ мужчин, родившихся в 2015 г., а до 60 лет - 90.3\% [9].

Актуальным остается гендерное неравенство в здравоохранении. Хотя охрана здоровья по Конституции РФ не обусловлена полом, женщины, в силу биологических особенностей, больше пользуются медицинскими услугами; особенно важны здесь гарантии репродуктивных прав - права на материнство, на предотвращение и прерывание нежелательной беременности и проч. При этом женщины демонстрируют повышенный уровень нездоровья из-за ограниченности доступа к здоровьесберегающим ресурсам и стресса, вызванного спецификой гендерных и семейных ролей. Препятствия, с которыми сталкиваются женщины, включают отсутствие культурно адаптированных форм оказания медицинской помощи, нехватку ресурсов, и даже запрет со стороны членов семьи, в результате чего при дефиците семейного бюджета потребности женщин в поддержании здоровья удовлетворяются в последнюю очередь. Вынужденный отказ от медицинских услуг, как и реструктуризация формы оказания услуг в сторону роста амбулаторно-поликлинического и сокращения стационарного лечения, увеличивают гендерную асимметрию, так как 
вслед за этим увеличивается нагрузка женщин в домохозяйстве; особенно это касается работающих женщин молодого и среднего возраста. Для здравоохранения как отрасли экономики ситуация осложняется ярко выраженной феминизацией отрасли, где женщины составляют более $70 \%$ занятых [8].

Традиции самосохранительного поведения в России еще не сформированы, поскольку население вынуждено вкладывать «здоровье в доход», а не «доход в здоровье», как в развитых странах - у россиян нет дохода, который можно вкладывать в свое здоровье.

Одной из самых значимых детерминант накопления человеческого капитала является образование. На смену индустриальному обществу приходит информационное, мир развивается в условиях глобализации, что требует постоянного обновления знаний в соответствии с последними научными достижениями. Знания стремительно устаревают, даже за период школьных лет одного ребенка, а образование не связано напрямую с теми сферами, для которых готовит специалистов - большинство выпускников высших и средних профессиональных предоставлены сами себе в трудоустройстве и далеко не всегда работают по специальности. Сама система образования предполагает развитие миграционных процессов: дети в сельских школах получают знания, которые будут востребованы в городах, а затем за границей. Идея такого образования была сформулирована и реализована в СССР, но тогда региональный баланс интеллектуальных ресурсов регулировался системой распределения молодых специалистов. Сейчас же обратный поток специалистов из центра в регионы ничтожен.

По переписи населения 2010 г. 33\% населения России имели общее образования, $36 \%$ - профессиональное образование, $26 \%$ высшее и неполное высшее (рассчитано по [4]), 720 тыс. человек указали на наличие ученой степени кандидата наук или доктора наук. Среди кандидатов наук почти две трети (64.6\%) были в трудоспособном возрасте, среди докторов наук более половины - старше трудоспособного возраста (51.4\%) (рассчитано по [4]). Несмотря на достаточно высокую образованность населения России, в стране ощущается острая нехватка квалифицированных рабочих, мастеров, инженеров, место которых занимают менеджеры, часто незнакомые со спецификой производства. 
Русанова Н.Е. Население России в XXI в.: количественные и качественные.., стр. 75-82 Rusanova N.E. Population of Russia in XXI century: quantitative and qualitative..., pp. 75-82

Заключение. Таким образом, при низкой рождаемости и периодической депопуляции вопросы о том, сколько будет населения в следующих поколениях и с какими качествами, становятся для государства самыми главными. При углублении процессов демографического старения сохранение здоровья населения и поддержание образования на уровне, соответствующем социальноэкономическим потребностям общества, государственных мер регулирования систем здравоохранения и образования недостаточно, необходимо ответное участие населения. Достаточно заметно это проявляется, например, при формировании индивидуального самосохранительного поведения с учетом общей медикализации жизни.

\section{СПИСОК ЛИТЕРАТУРЫ}

1. Федеральный закон от 21.11.2011 N 323-Ф3 (ред. 27.12.2018 с изменениями, вступившими в силу с 31.01.2019) «Об основах охраны здоровья граждан в Российской Федерации».

URL: http://kodeks.systecs.ru/zakon/fz-323/

2. Государственная программа Российской Федерации "Развитие здравоохранения" Уточненный отчет о ходе реализации и оценке эффективности государственной программы Российской Федерации «Развитие здравоохранения» за 2017 год. URL: https://bit.ly/2Jzd2E1

3. Здравоохранение 2015. Статистический сборник. М., 2015. URL: http://www.gks.ru/free_doc/doc_2015/zdrav15.pdf.

4. Итоги Всероссийской переписи населения 2010 г. т.3. Образование. URL: http://www.gks.ru/free_doc/new_site/perepis2010/croc/perepis_itogi1612.htm

5. Корсак В.С., Смирнова А.А., Шурыгина О.В. ВРТ в России 2013. Регистр ВРТ. 19 ежегодный ретроспективный отчет. СПб., 2015.

6. Национальный регистр ВРТ за 2016 г., с.48.

URL: http://www.rahr.ru/d_registr_otchet/RegistrART2016.pdf

7. Распределение численности населения Российской Федерации по полу и возрастным группам на 1 января 2018 года.

URL: http://www.gks.ru/wps/wcm/connect/rosstat_main/rosstat/ru/statistics/ population/demography/

8. Скворцова: в России 70\% врачей — женщины. URL: https://78.ru/news/2018-0920/skvorcova_v_rossii_70_vrachei_zhenshini

9. Старостина Ю., Фейнберг А. Неравные шансы: как эксперты оценили вероятность дожить до пенсии.

URL: https://www.rbc.ru/economics/27/06/2018/5b30dd609a7947d89ccaa56e 


\section{POPULATION OF RUSSIA IN XXI CENTURY: QUANTITATIVE AND QUALITATIVE CHARACTERISTICS}

\section{Rusanova N.E.}

Traditionally, the value of the population as a factor of socio-economic development was estimated by quantitative parameters, but at the postindustrial stage, the characteristics of human capital came to the fore. Although the overall quantitative indicators show an improvement in the health and education situation of the population, their quality in the context of demographic ageing cannot be considered favorable due to the reduced potential of health and structural mismatch of education to the needs of economic development. 